\title{
REVIEW ARTICLE OPEN Protein synthesis, degradation, and energy metabolism in T cell immunity
}

\author{
Julia M. Marchingo $\mathbb{D}^{1}$ and Doreen A. Cantrell ${ }^{1 凶}$
}

(c) The Author(s) 2021

T cell activation, proliferation, and differentiation into effector and memory states involve massive remodeling of T cell size and molecular content and create a massive increase in demand for energy and amino acids. Protein synthesis is an energy- and resource-demanding process; as such, changes in T cell energy production are intrinsically linked to proteome remodeling. In this review, we discuss how protein synthesis and degradation change over the course of a T cell immune response and the crosstalk between these processes and T cell energy metabolism. We highlight how the use of high-resolution mass spectrometry to analyze $\mathrm{T}$ cell proteomes can improve our understanding of how these processes are regulated.

Keywords: T lymphocyte; Protein Translation; Proteomics; Immunometabolism; Protein degradation

Cellular \& Molecular Immunology (2022) 19:303-315; https://doi.org/10.1038/s41423-021-00792-8

\section{INTRODUCTION}

Upon pathogen recognition, naive $T$ cells rapidly increase energy production and produce a large number of new messenger RNA (mRNA) transcripts and proteins. Activated T cells also undergo massive growth, doubling to quadrupling in size over a 1-2 day period [1-3], followed by a rapid series of cellular divisions every 6-12 h [4]. This complete overhaul of the cellular transcriptome and proteome results in substantial remodeling of multiple pathways involved in cellular metabolism and protein synthesis, including key energy production pathways governing mitochondrial, glycolytic and lipid metabolism; pathways important for the synthesis of biomolecules, such as nucleotides, amino acids and fatty acids; and ribosomal protein production machinery, as outlined in several proteome resource studies [2, 5-7]. These changes support the massive clonal expansion of pathogenspecific T cells and their differentiation into effector cell subsets, where they function as protein production factories for effector molecules, including inflammatory cytokines and cytolytic granzymes. After pathogen clearance, the effector $\mathrm{T}$ cell population contracts, whereas memory $T$ cells persist in a quiescent state, ready for reactivation if reinfection occurs.

The protein production and degradation that drive $\mathrm{T}$ cell activation are energy- and resource-intensive processes that are shaped by the $T$ cell environment and the availability of key nutrients [8-10]. In this review, we will primarily focus on how immune-activated $\mathrm{T}$ cells control protein synthesis. We will also discuss how protein synthesis and degradation are regulated by $\mathrm{T}$ cell energy metabolism. Throughout the review, we will highlight how information in publicly available $\mathrm{T}$ cell proteomics datasets (listed in Table 1) can enhance our understanding of protein synthesis control and T cell metabolic pathways.

\section{GENERAL OVERVIEW OF PROTEIN SYNTHESIS}

Protein synthesis involves linking amino acids into a polypeptide chain in the order specified by the nucleotide sequence of a mRNA transcript. A simplified diagram of protein synthesis is provided in Fig. 1a. The ribosome, a macromolecular complex composed of ribosomal RNA (rRNA) and many ribosomal proteins, is the molecular machine that facilitates protein synthesis. Amino acids are brought to the ribosome by transfer RNAs (tRNAs). For each codon in mRNA that is translated into protein, there is at least one tRNA that contains the matching anti-codon and thus carries the corresponding amino acid. Each ribosome consists of two subunits that have distinct functions and must be brought together for protein synthesis to occur. The small (40 S) subunit binds the mRNA and contains the site where the tRNA anti-codon is matched to the complementary mRNA sequence. The large (60 S) subunit contains the site where the peptide bonds between amino acids brought to the ribosome by tRNA are formed, ultimately generating the polypeptide chain that is subsequently folded to form the final protein structure. As illustrated in Fig. 1b, mRNA can be associated with a single complete $(80 \mathrm{~S})$ ribosome, referred to as a monosome, or translated simultaneously by multiple ribosomes in a structure called a polysome. Once the ribosome reaches a termination codon, for which there is no matching tRNA, translation terminates, and the ribosomal subunits dissociate and are recycled for use in another round of translation [11, 12].

Translation of an mRNA sequence into a protein is frequently described as involving three main steps: translation initiation, elongation and termination (Fig. 1a) [11-13]. A major point of protein synthesis regulation is at translation initiation. All mammalian mRNAs are marked with a methylated guanosine cap at their $5^{\prime}$ end during RNA polymerase II-mediated

${ }^{1}$ Cell Signalling and Immunology Division, School of Life Sciences, University of Dundee, Dundee DD1 5EH, UK. ${ }^{凶}$ email: d.a.cantrell@dundee.ac.uk 
Table 1. List of highlighted proteomics resources

\begin{tabular}{|c|c|c|}
\hline Reference & Mass spec technique & Cell type/stimulation condition \\
\hline Damasio [1] & $\begin{array}{l}\text { TMT-labeled } \\
\text { fractionated DDA }\end{array}$ & $\begin{array}{l}\text { Mouse T cells, } 3 \text { biological replicates: } \\
\text {-CD8 Naive } \\
\text {-CD8 } 24 \mathrm{~h} \text { peptide treatment } \\
\text {-CD8 } 24 \mathrm{~h} \text { peptide + Mek inhibitor treatment }\end{array}$ \\
\hline Howden* [2] & $\begin{array}{l}\text { TMT-labeled } \\
\text { fractionated DDA }\end{array}$ & $\begin{array}{l}\text { Mouse T cells, } 3 \text { biological replicates: } \\
\text {-CD8 Naive } \\
\text {-CD4 Naive } \\
\text {-CD8 treated for } 24 \mathrm{~h} \text { with peptide + IL2/IL12 } \\
\text {-CD4 treated for } 24 \mathrm{~h} \text { with peptide/APC + IL2/IL12 } \\
\text { - CTLs in vitro generated with IL2/12 } \\
\text { - Th1 in vitro generated with IL2/12 } \\
\text {-All activated T cell subsets treated for } 24 \mathrm{~h}+/ \text { - rapamycin }\end{array}$ \\
\hline Hukelmann [33] & $\begin{array}{l}\text { SILAC-labeled } \\
\text { fractionated DDA }\end{array}$ & $\begin{array}{l}\text { Mouse T cells, } 3 \text { biological replicates: } \\
\text {-CTLs in vitro generated with IL2/IL12+/- rapamycin for the } \\
\text { final } 48 \mathrm{~h}\end{array}$ \\
\hline Ma [36] & $\begin{array}{l}\text { TMT-labeled } \\
\text { fractionated DDA }\end{array}$ & $\begin{array}{l}\text { Mouse T cells, } 5 \text { biological replicates: } \\
\text {-Naive and activated OT1 CD8 T cells from day } 2.5 \text { of a } \\
\text { Listeria-OVA infection }\end{array}$ \\
\hline Marchingo [3] & Label-free fractionated DDA & 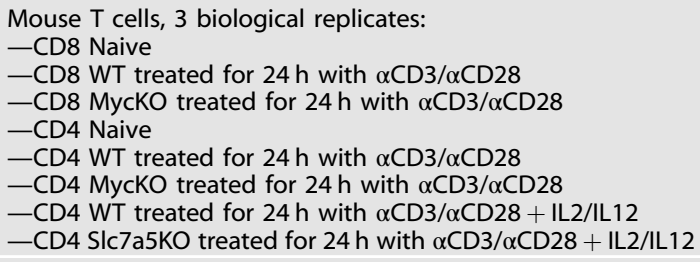 \\
\hline Rieckmann [42] & Label-free single-shot DDA & $\begin{array}{l}\text { Human T cells and other hematopoietic lineages, } 4 \text { biological } \\
\text { replicates: } \\
\text { - CD } 4 / \text { CD } 8 \text { Naive, memory T cells, and effector memory } \\
\text { T cells at steady state or activated for } 48 \mathrm{~h} \text { with } \alpha \mathrm{CD} 3 / \alpha \mathrm{CD} 28 \\
\text { and then cultured for } 48 \mathrm{~h} \text { with IL2 } \\
-\mathrm{CD} 4 \mathrm{Th} 1, \mathrm{Th} 2 \text {, and Th17 at steady state }\end{array}$ \\
\hline Rollings [37] & Label-free fractionated DDA & $\begin{array}{l}\text { Mouse T cells, } 3 \text { biological replicates: } \\
\text { - In vitro IL2-expanded CTLs treated for } 24 \mathrm{~h}+/- \text { IL2 } \\
\text { - In vitro IL2-expanded CTLs treated for } 24 \mathrm{~h}+/- \text { Jak1/3 } \\
\text { inhibitor }\end{array}$ \\
\hline Ross [38] & $\begin{array}{l}\text { SILAC-labeled } \\
\text { Fractionated } \\
\text { DDA }\end{array}$ & $\begin{array}{l}\text { Mouse T cells, } 3 \text { biological replicates: } \\
\text { - In vitro IL2-expanded CTLs treated overnight in IL12 only } \\
\text { then }+/- \text { IL2 for } 15 \mathrm{~min} \\
\text { - In vitro IL2-expanded CTLs treated for } 30 \mathrm{~min} \text { or } 4 \mathrm{~h} \text { with } \\
\text { Jak1/3 inhibitor } \\
\text { - In vitro IL2-expanded CTLs treated for } 4 \mathrm{~h} \text { with Src family } \\
\text { inhibitor }\end{array}$ \\
\hline $\operatorname{Tan}^{*}[6]$ & $\begin{array}{l}\text { TMT-labeled } \\
\text { fractionated DDA }\end{array}$ & $\begin{array}{l}\text { Mouse T cells, } 2 \text { biological replicates } \\
\text { - Naive CD4 T cells } \\
\text { - } \alpha \mathrm{CD} 3 / \alpha C D 28 \text {-activated WT CD4 T cells after } 2,8 \text {, or } 16 \mathrm{~h} \\
-\alpha \mathrm{CD} 3 / \alpha C D 28 \text {-activated Raptor KO CD4 T cells after } 2 \text { or } 16 \mathrm{~h}\end{array}$ \\
\hline Wolf* [7] & $\begin{array}{l}\text { SILAC-labeled } \\
\text { Single-shot DDA }\end{array}$ & $\begin{array}{l}\text { Human T cells, 3-7 biological replicates: } \\
\text {-Naive/Memory CD4 T cell protein turnover (SILAC labeling } \\
\text { time course) } \\
\text {-Naive CD4 T cells treated for } 24 \mathrm{~h} \text { (control, + translation } \\
\text { inhibitor, or }+ \text { translation and proteasome inhibitor) } \\
\text { - Naive or } \alpha C D 3 / \alpha C D 28 \text {-activated CD4 T cells at } 6,12,24,48 \text {, } \\
72,96,120 \text {, and } 144 \mathrm{~h} \\
\text { - RNAseq data for Naive and } \alpha C D 3 / \alpha C D 28 \text {-activated CD4 } \\
\text { T cells at } 6 \text { and } 24 \mathrm{~h}\end{array}$ \\
\hline
\end{tabular}

Information available

Whole cell proteome

Copies/cell

Fold change, statistics

Whole cell proteome

Copies/cell

Concentration (nM)

Mass (pg)/cell

Fold change, statistics

website: immpres.co.uk

Whole cell proteome

Copies/cell, fold change, statistics

Whole cell proteome

Summed peptide intensities

Whole cell proteome

Copies/cell

Mass (pg)/cell

Fold change, statistics

website: immpres.co.uk

Whole cell proteome

Summed peptide intensities, LFQ, iBAQ, copies/cell

website: immprot.org

Whole cell proteome

Copies/cell

Fold change, statistics

Phosphoproteome

SILAC ratio of summed peptides, stats

Whole cell proteome and phosphoproteome

Summed peptide intensities, fold change, statistics

Whole cell proteome

Turnover kinetics (naive, memory), copies (CHX experiment)

LFQ, copies (activation time course)

Estimated transcript/cell

website: immunomics.ch

Resource papers are studies of primary human or mouse T cells. For whole cell proteome studies, authors included intensity/copy number information as well as fold changes and statistics as Supplementary Tables or on Websites, therefore making data accessible for flexible interrogation by all readers without the need to reanalyze raw files.

An asterisk indicates studies that are particularly useful for understanding changes in protein expression over time.

transcription. The cap structure is critical for binding proteins that control translation initiation by recruiting mRNA to the ribosome or translation repression by preventing ribosome interaction [1315]. Most mRNAs in mammalian cells are recruited for translation via the elF4F complex, a heterotrimer consisting of the proteins elF4E, elF4G and elF4A $[12,13]$. As illustrated in Fig. 1C, elF4E binds the mRNA cap to recruit the mRNA for translation. Many mRNAs have secondary structures in their $5^{\prime}$ untranslated regions (UTRs). When eIF4A is bound to elF4G, it mediates the unwinding of these secondary structures through its RNA helicase activity, which can be enhanced by elF4B and elF4H. elF4G acts as the scaffold protein, enhancing elF4A activity and bringing elF4E-bound mRNA to the preinitiation complex (PIC). The PIC contains the small ribosomal subunit and a series of other translation initiation factors, including GTP-bound elF2, which mediates the binding of initiator tRNA. elF4G also recruits polyadenylate binding protein, which interacts with the 3' mRNA end, allowing transcript circularization and enhancing protein translation. Once recruited, 
A Basic steps in protein synthesis: Components:

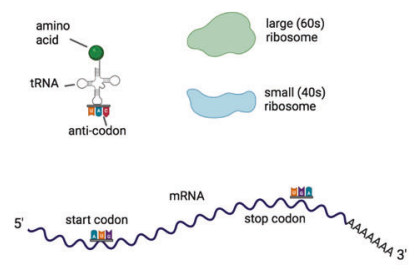

1) Initiation

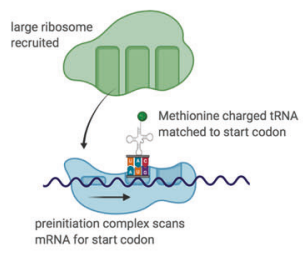

2) Elongation

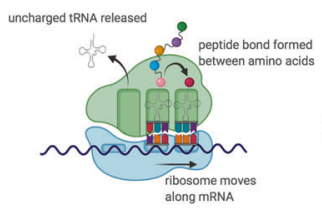

3) Termination

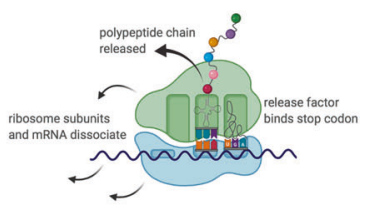

B Amount of ribosome recruited to mRNA:
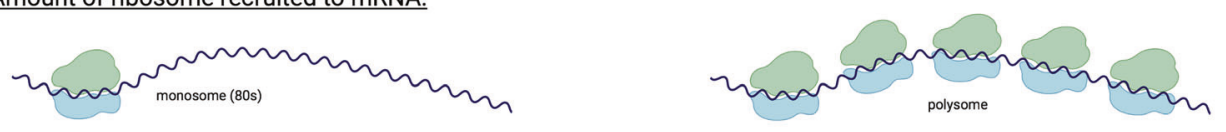

C The elF4F translation initiation complex
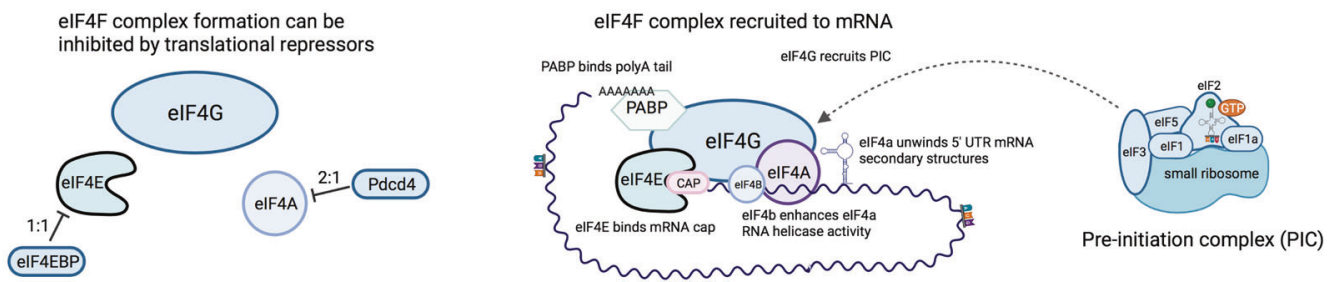

Fig. 1 Features of protein synthesis. A Basic schematic of the three major steps in protein synthesis: initiation, elongation, and termination. B A single ribosome recruited to $\mathrm{mRNA}$ is referred to as a monosome; when multiple ribosomes are simultaneously recruited to mRNA, the structure is called a polysome. C (Left) The translational repressors elF4EBP1-3 and PDCD4 can prevent elF4E and elF4A, respectively, from binding to the elF4G scaffold protein. (middle) Schematic of eIF4F recruitment to mRNA. (right) Schematic of the preinitiation complex

the PIC scans the mRNA for the translational start site, indicated by an AUG codon encoding the amino acid methionine. Once the start codon is identified and paired with methionine-charged tRNA, elF2-GTP is hydrolyzed and dissociates from the PIC, and the large ribosome is recruited. At this point, protein elongation commences $[12,13]$.

\section{HOW PROTEIN SYNTHESIS CAPACITY AND ACTIVITY CHANGE DURING A T CELL IMMUNE RESPONSE}

The following sections will outline how protein synthesis changes as naive $T$ cells respond to pathogens and differentiate into effector and memory cells. A schematic of the changes in nutrient uptake, protein synthesis, and cell metabolism is provided in Fig. 2.

\section{Naive T cells}

In naive T cells, the rate of protein synthesis is low [16-18] but not zero, and naive $T$ cells synthesize a surprisingly large number of proteins [19]. A recent study measuring protein turnover revealed that $19 \%$ of protein species detected in naive human CD4 T cells were at least partially degraded and regenerated over a 24-h period in culture [7]. In this study, estimates of individual protein turnover rates in naive $T$ cells varied widely; some proteins had renewal half-lives of $<1 \mathrm{~h}$ (such as ETS1), whereas others had renewal half-lives of $>200 \mathrm{~h}$ (e.g., GAPDH) [7]. Critically, the continued synthesis of new proteins in naive T cells is functionally important. Many transcription factors and survival and homing proteins (e.g., IL7R, CD62L, TCF1, and FOXO1) required for naive T cell maintenance are rapidly turned over [7], consistent with the result that naive $T$ cell quiescence is actively maintained $[20,21]$.

One estimate by Wolf et al. is that naive T cells translate $\sim 60,000$ proteins/min [7]. These findings of substantial translation in naive T cells are supported by a ribosome profiling study that found that $\sim 23 \%$ of mRNAs were enriched for ribosome-protected fragments in naive mouse CD4 T cells [19]. Naive T cells have a sizeable pool of ribosomal subunits; proteomics and rRNA measurements have yielded estimates of $\sim 400,00-700,000$ ribosomes per cell [2, 7]. However, the majority of these ribosomes are not thought to be actively engaged in translation. The translationally active ribosome pool is in polysomes (Fig. 1b), but multiple polysome profiling studies in naive $\mathrm{T}$ cells have reported the presence of very few polysomes, with most RNA in subpolysome fractions $[16,17,22,23]$. Whether protein synthesis in naive $T$ cells occurs in monosomes or in the few polysomes present is not known. However, recent work in yeast and rat neurons has indicated that contrary to dogma, monosomes can substantially contribute to cellular protein synthesis [24, 25].

\section{T cell activation}

It has been known since the 1960s that stimulated leukocytes increase in size prior to entering the cell cycle [26]. During a T cell response, this 'blasting' phenomenon is triggered by $\mathrm{T}$ cell receptor (TCR) signaling, which drives a major increase in protein synthesis and large-scale proteome remodeling before the first cell division. Initial changes in protein synthesis can occur rapidly, with thousands of copies of hundreds of new protein species being produced within a few hours of activation [5-7]. Wolf et al. have estimated that within $6 \mathrm{~h}$ of TCR activation, T cells are translating $\sim 300,000$ proteins/min, a 5-fold increase compared to the rate in naive T cells [7]. Generally, substantial cell growth and the amplification of protein synthesis do not begin until at least $8-12 \mathrm{~h}$ post TCR triggering in vitro [5-7,27], and large increases in size have been observed by $24 \mathrm{~h}$ post activation both in vitro and in vivo [28]. Wolf et al. estimated that by $24 \mathrm{~h}$ after TCR activation in vitro, T cells are synthesizing $\sim 800,000$ proteins $/$ min. Protein synthesis continues to increase for $1-2$ days as cells prepare to commence a rapid division phase. 
A

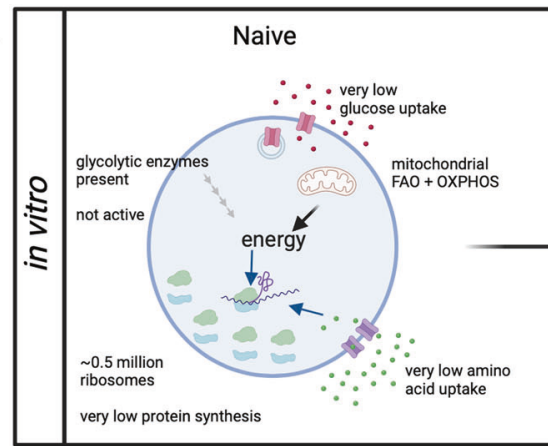

Early TCR activation (4-6 hrs)

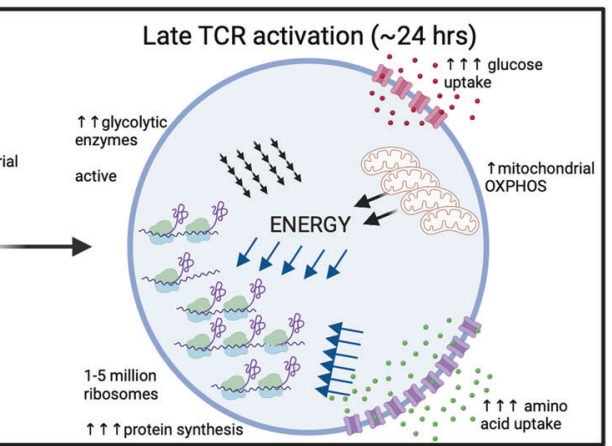

B
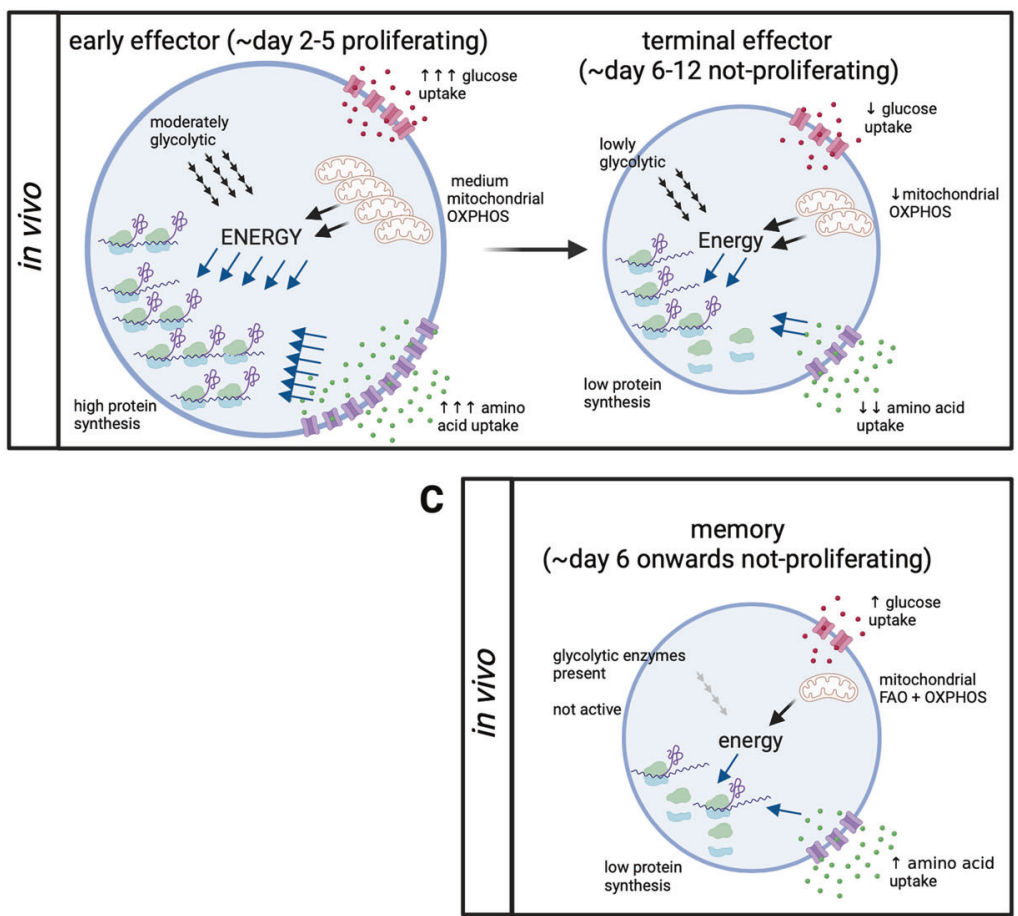
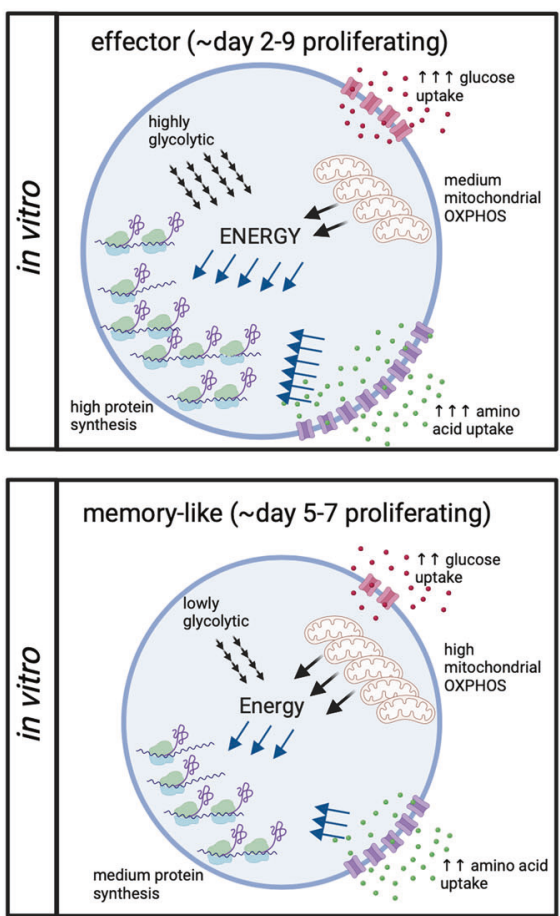

Fig. 2 Protein synthesis and energy production during in vitro and in vivo T cell responses. Changes in amino acid uptake (via purple transporters); glucose uptake (via red transporters); ribosome assembly and protein synthesis; and energy (ATP) production via glycolysis (diagonal $4 \times$ arrows) and mitochondrial oxidative phosphorylation (OXPHOS) or fatty acid oxidation (FAO) in A ex vivo naive and in vitro 6 and $24 \mathrm{~h}$ TCR-activated T cells; in vivo and in vitro generated B effector T cells; and C memory T cells. A Naive T cells have very low nutrient uptake, protein synthesis, and energy production. T cell activation increases protein synthesis and energy production by increasing nutrient uptake and engaging preformed protein machinery before further increasing the expression of nutrient transporters, metabolic machinery, and ribosomes to support large-scale cell growth. B, C In vivo activated cells maintain a high growth phenotype only while they proliferate, whereas nutrient uptake, energy production, and protein synthesis are reduced when they terminally differentiate into effector or memory T cells. In vitro-generated T cells maintain a high growth phenotype for the entire culture period, with effector (IL2-cultured) T cells exhibiting a higher pro-growth phenotype than memory-like (IL15-cultured) T cells

Measurable $\mathrm{T}$ cell growth corresponds with the increased expression of ribosomal proteins and other translational machinery $[5-7,23]$. By a series of elegant calculations using time course proteomics data, Wolf et al. estimated that ribosomes translate $\sim 4$ amino acids/sec at both 6 and $24 \mathrm{~h}$ post TCR stimulation [7], indicating that the increased protein synthesis capacity of immune-activated $T$ cells is likely due to higher quantities of ribosomes and translational machinery and not changes in ribosome activity $[7,29]$. In vitro proteomics studies suggest that protein content increases by an estimated 3-4-fold after $24 \mathrm{~h}$ of TCR activation, and $\sim 50-70 \%$ of the proteome is altered compared to that in naive $\mathrm{T}$ cells. The majority of these changes are increases, with $50-60 \%$ of total proteins detected being newly expressed or upregulated by more than 1.5 -fold [1-3].

Some proteome remodeling during $T$ cell activation requires de novo mRNA production, including the expression of mRNA encoding transcription factors, cytokines, and chemokines, which are critical for immune cell activation and function [7, 28, 30, 31]. Indeed, the immune activation of $\mathrm{T}$ cells initiates large-scale remodeling of the transcriptome, with numerous mRNAs being created or destroyed. A modest 1.4-fold increase in total mRNA content was observed $6 \mathrm{~h}$ post immune activation in vitro [7], with a more substantial $\sim 5-10$-fold increase within $20-24 \mathrm{~h}$ post activation [7, 32]. Despite this, mRNA quantity only moderately correlates with protein expression levels during $T$ cell activation and in differentiated cytotoxic $\mathrm{T}$ lymphocytes (correlation coefficient ranging from 0.4 to 0.65$)[6,7,33]$. Preformed transcripts, which are present but not translated in naive $T$ cells, contribute to this disconnect, although they encode only $\sim 3 \%$ of detected protein species [7]. Such preformed transcripts include those for important proteins such as the AP-1 transcription factors JUNB and FOS and the glucose transporters SLC2A1 and SLC2A3 (GLUT1 and 3, respectively) [7, 17]. Other translational and posttranslational mechanisms, such as translational control by 
other RNA-binding proteins (RBPs), differences in mRNA and protein modification and stability, and temporal differences between mRNA and protein expression, also contribute substantially to the mRNA/protein discrepancies observed in T cells, as discussed elsewhere [34, 35].

\section{Effector and memory $T$ cells}

The magnitude of the increase in global protein synthesis during effector T cell differentiation is dependent on the system and time point studied, as outlined in Fig. 2b. During an in vivo CD8 T cell response, TCR-activated $T$ cells increase in mass and remain large for a period of several days while they rapidly proliferate $[4,16,28]$. During this time, they show high mRNA and protein expression of translational machinery $[28,36]$, a high polysome content and high amounts of protein synthesis [16]. By the peak of T cell expansion (a time point regularly assayed to assess differentiated effector and memory phenotypes), the cells are no longer dividing, and the differentiated effector $T$ cells are small, with a protein synthesis rate lower than at earlier activation timepoints but still higher than that in naive T cells $[4,16,28]$. These in vivo changes in protein synthesis rates in effector CD8 $T$ cells temporally correlate with the translational repression of mRNA encoding ribosomal subunits and translation initiation factors. Hence, the capacity for protein synthesis is actively controlled during a $T$ cell response and appears to be closely linked to both the initiation and cessation of $T$ cell division [16].

When effector CD4 and CD8 T cells proliferate and differentiate in vitro in nutrient-rich media in the presence of inflammatory cytokines, they can sustain the high levels of expression of ribosomes and translational machinery. As a consequence, in vitro-generated effector $T$ cells remain extremely translationally active with high levels of protein synthesis (Fig. 2b) [2, 33, 37, 38]. This phenotype is a consequence of the inclusion of growth factors such as IL2 in culture medium and the use of high nutrient media to maintain effector T cells in culture. Indeed, the ability of IL2 to drive high levels of protein synthesis to sustain T cell size and proliferation is the reason this cytokine is so widely used to generate effector T cells in vitro [39]. In the absence of IL2, in vitro cultured $T$ cells undergo a rapid reduction in protein synthesis, cease dividing and eventually die [4, 37, 39]. The use of other cytokines, such as IL15, to maintain T cells in vitro leads to low rates of protein synthesis and in fact does not promote the production of effector $\mathrm{T}$ cells but rather promotes the differentiation of smaller memory-like T cell populations (Fig. 2c) [40,41].

Effector T cells produce cytokines and cytolytic molecules that drive pathogen clearance and express high levels of effector molecule mRNAs, including those encoding granzyme B and IFNץ. Granzyme $B$ is one of the most highly expressed proteins in effector CD8 T cells $[2,7,33,37,42]$. Irrespective of the discrepancy in global protein synthesis rates, granzyme B is highly translated at time points corresponding to both proliferating and nonproliferating effector T cells in vivo [16]. In contrast, the posttranscriptional regulation of cytokine expression has frequently been observed in activated and effector T cells. For example, IFNy mRNA is highly expressed in effector CD8 T cells during an in vivo response. At early time points, high IFNy protein expression correlates with high IFNy mRNA polysome occupancy. However, at the peak of cell expansion, when global protein synthesis rates are low, the amount of IFNy mRNA associated with the polysome is substantially reduced, corresponding with a reduction in IFN $\gamma$ protein production and secretion [16]. This finding is consistent with the results of multiple studies showing that IFNy expression in T cells is exquisitely controlled in a posttranscriptional manner due to its highly regulated 3'UTR [43-45] and potentially through the structure of its 5'UTR [46]. IFNy is not the only cytokine that is controlled at the posttranscriptional level. IL4 and IL10 expression has been reported to be high at the mRNA level but repressed at the protein level in self-reactive 'anergic' CD4 T cells [45], whereas IFNY, IL4, and IL10 protein levels are increased in activated $\mathrm{T}$ cells deficient in the translation repressor PDCD4 [47]. IFNy and IL17 production can also be repressed by inhibitors of the elF4F translation initiation complex [17]. Of note, even in translationally active in vitro-generated T cells, pharmacological or TCR stimulation is often required to reveal the cytokine production potential of the $T$ cell population. For the cytokines IFNY and TNFa, this involves the release of the translational repression of preformed transcripts, followed by de novo mRNA transcription [48]. For IL4 and IL2, de novo mRNA transcription is required for cytokine production $[48,49]$. Similar to effector T cells, memory $\mathrm{T}$ cells also contain preformed cytokine mRNAs, and recent work demonstrated that the RBP ZFP36L2 repressed IFN $y$ and TNFa mRNA until cells were retriggered through the TCR [44].

\section{REGULATORS OF THE PROTEIN SYNTHESIS RATE IN T CELLS}

T cells undergo major transitions in protein synthesis activity when they are activated, proliferate and differentiate. The immunological drivers of the increased protein synthesis that supports $T$ cell activation, proliferation, and effector function are signals generated by the T cell antigen receptor and inflammatory cytokines [1$3,5-7,33,37,38]$. In this section, we will outline the major factors that control protein synthesis: (1) antigen receptor- and cytokinedriven increases in amino acid availability, (2) the expression and activity of translational repressor proteins, and (3) the posttranslational modification of translation initiation factors.

\section{Sourcing amino acids-a key regulator of $\mathrm{T}$ cell protein synthesis}

T cells can obtain the amino acids needed to fuel protein synthesis by four main mechanisms: uptake from the environment via amino acid transporters [50, 51], degradation of extracellular proteins internalized by macropinocytosis [52], metabolic pathways that convert other metabolites into amino acids [36,53], and degradation of intracellular proteins via autophagy [54]. Amino acids can be classified as either essential (His, Iso, Leu, Lys, Met, Phe, Thr, Trp, and Val), meaning they must be acquired from food, or nonessential, encompassing amino acids that can be enzymatically synthesized by cells from other biomolecules, such as glucose and essential amino acids. T cells must import essential amino acids, as they are unable to synthesize them. However, T cells also rely on an extrinsic supply of nonessential amino acids, as they either synthesize insufficient amounts or lack the specific machinery to meet the biosynthetic demand during activation. Thus, $T$ cells are sensitive to the dietary and microenvironment levels of essential and certain nonessential amino acids, and changes in these levels can modulate T cells [36, 55-57]. Here, we focus on the environmental uptake of amino acids, as this appears to be the major mechanism by which $T$ cells source amino acids during activation and proliferation. Naive $T$ cells express very low levels (hundreds or a few thousand copies per cell) of amino acid transporters and take up only low amounts of amino acids $[2,3,18,51,58,59]$. Upon antigen receptor-driven $T$ cell activation, the expression of amino acid transporters is induced within $3-4 \mathrm{~h}$ of TCR triggering, supporting the increased amino acid uptake rate $[3,18,51]$. Expression of the key amino acid transporters SLC7A5 (Met, Leu, Iso, Trp, and Val), SLC1A5 (Gln, Ala, Cys, and Met), SLC7A1 (Arg and Lys), SLC38A1 and SLC38A2 (both Gln and Met) increases progressively over the course of $T$ cell activation; these transporters are some of the most induced proteins in the entire proteome, increasing by up to 100 -fold by $24 \mathrm{~h}$ of antigen activation $[2,3,18]$. Increases in amino acid transport substantially precede any change in the protein content of ribosomes and translation initiation factors $[6,7,23]$. The key immune signals that control amino acid transporter expression are generated by the $T$ cell antigen receptor and cytokines such as IL2. The T cell antigen receptor activates signaling pathways that trigger NFAT and NFKB 


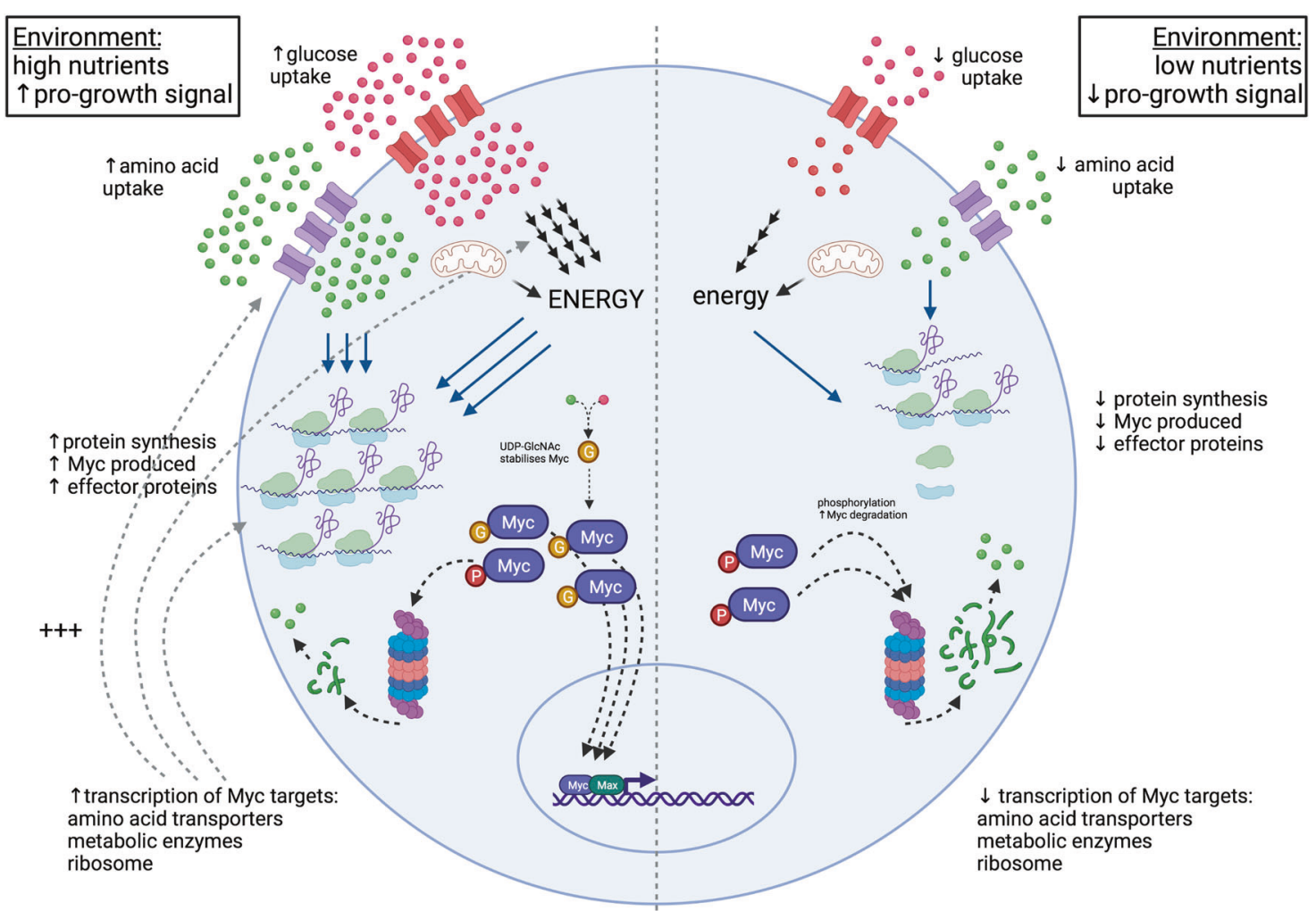

Fig. 3 MYC regulation: an example of how feedback among protein synthesis, cell metabolism, and protein degradation controls $\mathrm{T}$ cell function. Under high nutrient environments and/or high pro-growth signaling, there are high levels of amino acid and glucose uptake. This fuels high energy (ATP) production, supporting high levels of protein synthesis and the production of UDP-GlcNAc from glutamine and glucose. O-GlcNAcylation at Thr58 stabilizes MYC and prevents its proteasomal degradation. Increased MYC expression promotes the transcription of mRNA for the synthesis of proteins, including amino acid transporters, metabolic enzymes, and ribosomes, thus creating a positive feedforward loop to support a highly biosynthetic environment and sustain high MYC expression. This environment supports the high expression of effector proteins. In contrast, in low nutrient conditions and/or low pro-growth signaling, there is low amino acid and glucose uptake. This results in low energy production and limited fuel and biomolecules for the synthesis of effector proteins. Less MYC is synthesized, and thus, less MYC is O-GIcNAcylated, increasing the proteasomal degradation of MYC. This feedback reduces the MYC-mediated transcription of pro-growth mRNAs

family protein-driven transcription of the key transcription factor MYC [51, 60, 61]. MYC is required for the expression of Slc7a5 and Slc1a5 mRNA, and there is no substantial increase in any amino acid transporter protein upon $\mathrm{T}$ cell activation in the absence of MYC [3]. Accordingly, in the absence of MYC, T cells fail to increase amino acid uptake or protein content in response to immune activation [3, 62]. Strikingly, deficiency in a single amino acid transporter, SLC7A5, is sufficient to phenocopy the effects of MYC deficiency, preventing most $T$ cell growth and protein synthesis [3]. In effector T cells, cytokine-induced JAK tyrosine kinase signaling is important for maintaining MYC expression and amino acid uptake [38, 63]. Moreover, JAK inhibition is sufficient to dramatically reduce amino acid uptake and protein synthesis in response to the cytokine IL2 $[38,63]$. In both antigen-activated and effector $T$ cells, high levels of amino uptake are required to sustain high levels of MYC protein expression, thus creating a positive feedforward loop involving amino acid uptake, MYCdriven protein synthesis and cell metabolism (Fig. 3) [3, 18, 51, 63].

It has been extensively demonstrated that environmental nutrient availability is key for $\mathrm{T}$ cell protein synthesis and growth. Depletion of a number of individual amino acids (Met, Ala, Arg, Asn, and GIn) in T cell culture media has been demonstrated to be sufficient to substantially inhibit $\mathrm{T}$ cell growth and protein synthesis during activation and differentiation $[18,51,53,64-$ 68]. Similarly, preventing amino acid acquisition by inhibiting the macropinocytosis of serum proteins causes a major defect in cell growth during $\mathrm{T}$ cell activation in vitro [52]. Extrinsic amino acid availability is also critical for T cells in vivo. Mouse studies have shown that dietary deficiency of methionine or glycine/serine results in reduced $\mathrm{T}$ cell expansion and effector functionality in response to antibacterial or autoimmune responses [36, 55]. Local competition with tumor cells for methionine also suppresses CD8 $T$ cell numbers and effector cytokine production, which can be enhanced by dietary methionine supplementation [56]. Similarly, oral supplementation with arginine has been shown to enhance an antitumor $T$ cell response in mice [58].

Amino acids are needed by T cells as they are the biosynthetic building blocks of protein synthesis. However, other pathways of amino acid metabolism are equally important; for example, methionine is important for producing the methyl donor used for DNA, RNA, and protein methylation [18]; glutamine can be used as an energy source via glutaminolysis [62] or to generate UDP-GICNAc, the substrate of important glycosyl transferases [69]; and serine is important for purine biosynthesis [36]. T cells can show substantial flexibility in nutrient utilization from metabolic pathways that depend on nutrient availability and enzyme expression, which, in turn, can have a major impact on $\mathrm{T}$ cell functionality [70, 71]. For example, inhibition of glutamine metabolizing enzymes using a glutamine analog was recently shown to enhance tumor clearance in a mouse model because energy metabolism within tumor cells was inhibited and because the metabolic adaptation of $\mathrm{T}$ cells to enhance glucose and acetate utilization in response to this treatment enhanced their survival and tumor-killing capability [71]. 
It has, however, been shown that protein synthesis is the major user of amino acids in proliferating cell lines [9]. In particular, the reduced availability of amino acids results in an accumulation of uncharged tRNAs, which can bind and activate the kinase GCN2. GCN2 phosphorylates elF2a, preventing elF2 from being recycled to the GTP-bound state required for translation initiation and thus inhibiting global protein synthesis $[72,73]$. Whether GCN2 plays a major regulatory role in controlling global protein synthesis in $T$ cells and is a major signaling factor through which amino acid deprivation controls the $T$ cell response are unclear. Several studies have shown that GCN2 contributes to the inhibition of cell cycle progression in T cells and their survival under conditions of nutrient stress, but whether this occurs via its control of global protein translation has not been explored [65, 66, 74]. Furthermore, another study demonstrated that cell cycle inhibition in T cells under amino acid-restricted conditions was not rescued by GCN2 deficiency and that GCN2 deficiency itself affected the cell cycle in a manner independent of its role in amino acid sensing [75]. The integrity of amino-acyl charged tRNA is, however, known to be important for translational regulation in $\mathrm{T}$ cells; a recent study demonstrated that the cleavage of amino acid-charged tRNA resulted in reduced protein synthesis in naive and activated T cells [76]. Cellular amino acid levels also regulate the activity of the mammalian/mechanistic target of rapamycin complex 1 (mTORC1) signaling pathway [50, 51, 77, 78]. The role of this pathway in modulating $T$ cell protein synthesis is discussed below.

Translational repressors-how important are they in T cells? It is thought that low rates of protein synthesis in quiescent cells can be enforced by proteins known as translational repressors that modulate protein synthesis by inhibiting the function of elF4F translation initiation complexes. The major translational repressor proteins that have been studied in $\mathrm{T}$ cells are elF4EBP family proteins and PDCD4 (Fig. 1c). These proteins are predominantly thought to be regulated by the serine/threonine kinase mTORC1. The translational repressors elF4EBP1-3 bind elF4E in a 1:1 ratio and prevent its association with the scaffold protein elF4G. Phosphorylation of mouse elF4EBP1 at residues T36/45 or of elF4EBP2 at T37/46 by mTORC1 causes dissociation from elF4E, allowing incorporation into the elF4F complex [79]. Somewhat unusually, elF4EBP2 is the more abundant isoform found in T cells [79]. elF4EBP1 is phosphorylated via mTORC1-sensitive signaling pathways in both TCR- and IL2-stimulated T cells [6, 33, 48, 80]. Ectopic overexpression of constitutively active elF4EBP1 was shown to strongly inhibit TCR-activated $\mathrm{T}$ cell growth and proliferation; however, whether endogenous levels of elF4EBP1/2 have similar effects in T cells was not determined within this study [79]. Other researchers have reported that elF4EBP1/2 deletion did not substantially impact mTORC1 inhibition of CD4 T cell proliferation [81]. This raises the question-how important are elF4EBPs in linking $\mathrm{mTORC} 1$ to the regulation of $\mathrm{T}$ cell protein synthesis? Measurements of the stoichiometry between elF4E and elF4EBP proteins suggested that elF4EBP proteins are not major regulators of global protein synthesis in $T$ cells. elF4EBP1-3 proteins must be expressed in excess of elF4E to repress protein synthesis. However, quantitative mass spectrometry analysis of human naive T cells revealed that elF4EBP1-3 and elF4E are at an approximate ratio of only 1:2-5 [6, 7, 42]. Furthermore, elF4EBP proteins were not detected in mouse naive T cells, which had tens of thousands of copies of elF4E $[2,3]$. In activated and effector $T$ cells, an even more skewed stoichiometry has been measured, with elF4E outnumbering elF4EBP proteins by more than 100-fold in mouse effector T cells [2] and by $3-8$-fold in human cells $[7,42]$. These data indicate that elF4EBP protein content in $T$ cells is insufficient to prevent elF4E from associating with the elF4F complex. Instead, it is likely that elF4EBP modulation of elF4F activity has highly selective effects on a subset of elF4E-sensitive transcripts [13].
Another translation repressor that could be important in T cells is PDCD4, which binds elF4A at a 1:2 ratio and prevents its association with elF4G in the elF4F translation initiation complex [82]. Quantitative mass spectrometry analysis of $T$ cell proteomes revealed that PDCD4 is highly expressed in naive $\mathrm{T}$ cells $(200,000-400,000$ copies per cell) $[2,7]$. PDCD4 expression is rapidly reduced in the first few hours of $T$ cell activation [6], resulting in a change in the PDCD4: elF4A1 ratio from 1: 3 in naive cells to $1: \sim 120$ at $24 \mathrm{~h}$ in TCR-activated T cells [2]. This rapid reduction in PDCD4 expression in T cells corresponds with increased phosphorylation of Ser76, the RSK1 site [6], and likely also Ser67/71, the S6K1 sites. These phosphorylation events drive the swift proteasomal degradation of PDCD4 [83]. In PDCD4deficient mice, protein synthesis in total thymocytes or splenocytes showed a clear $~ 1.5-3$-fold increase [47], although whether naive $T$ cells specifically contribute to this translational increase is not clear. In activated T cells (in which PDCD4 content is already relatively low), Pdcd4 deletion caused a selective increase in the cytokines IFNY, IL4, and IL10 [47]. In vivo, PDCD4-deficient effector CD8 T cells also exhibited increased IFN $\gamma$ production in tumor models, resulting in delayed tumor growth [84].

\section{Control of protein synthesis in T cells: challenging the mTORC1 myth}

The importance of matching $T$ cell protein production to the demands of immune effector T cells has prompted a focus on the key signaling molecules that control T cell protein synthesis. In this context, there is a pervasive dogma that the serine/threonine kinase mTORC1, which is activated in T cells in response to antigens, cytokines, and nutrients (in particular, amino acids and glucose), is a major regulator of protein synthesis in T cells. This dogma stems from work on MTORC1 as a regulator of protein synthesis in yeast and nonlymphoid cells [85-87]. However, while it is clear that mTORC1 is a critical regulator of T cell differentiation and controls $\mathrm{T}$ cell homing $[77,88]$, its role in regulating protein translation in $\mathrm{T}$ cells is highly selective. Indeed, mTORC1independent signaling pathways are quantitatively more important for controlling protein synthesis in T cells [1-3,60], and while immune-activated T cells can increase cell protein mass 3-4-fold, inhibition of $\mathrm{mTORC} 1$ only reduced this mass by $\sim 20 \%[2,33,80]$. Similarly, the impact of the mTORC1 inhibitor rapamycin on $\mathrm{T}$ cell protein translation in an in vivo infection model was modest, with only a small reduction in polysome association seen for several of the ribosome mRNAs measured [16].

How does mTORC1 selectively control T cell protein synthesis? mTORC1 regulates the phosphorylation of numerous eukaryotic translation initiation factors, translational repressors, and ribosomal subunits in activated T cells. For example, mTORC1 controls the phosphorylation of the translational repressors elF4EBPs and PDCD4 [6]. However, as outlined earlier, none of these individual repressors appear to play a major role in controlling global protein synthesis in T cells. $T$ cell activation is also associated with increased mTORC1-regulated phosphorylation of elF4B at Ser422 [6], which is reported to increase the interaction of elF4B with elF3 and enhance translation initiation [89]. It is also well established that $\mathrm{T}$ cell activation induces RSK1- or mTORC1-controlled serine phosphorylation of the small ribosomal subunit protein S6 (RPS6) [90-92]. Indeed, flow cytometry measurements of RPS6 phosphorylation are frequently used to monitor the cellular activity of mTORC1 [51, 80, 90, 91]. Although this phosphorylation may be important in some cells [92], accumulating evidence indicates that it is not a critical switch for protein synthesis in T cells. Salmond et al. demonstrated that T cells in which wild-type RPS6 alleles were replaced with RPS6 alleles with mutations in all five phosphorylatable serine residues activate, grow, proliferate and differentiate normally [90]. Similarly, So et al. demonstrated that $\mathrm{T}$ cells deficient for the key RPS6 kinases S6K1 and S6K2 underwent growth and proliferation similar to wild-type cells 
[79]. A plausible mechanism for a more substantial selective effect of mTORC1 on protein synthesis in T cells involves the pathways that couple mTORC1 to the translational control of $5^{\prime}$ terminal oligopyrimidine tract (5'TOP) mRNAs, which include mRNAs encoding ribosomes and translation factors. While the exact regulatory mechanisms are still being determined, it is thought that 5'TOP-containing mRNA is bound by the repressive RBP Larp1, which releases the 5'TOP mRNA upon phosphorylation by mTORC1 [13, 32]. mTORC1-mediated Larp1 phosphorylation has been detected within $2 \mathrm{~h}$ of T cell activation [6]; moreover, within $6-24 \mathrm{~h}$ of TCR activation, the expression levels of proteins encoded by 5'TOP mRNAs were found to be sensitive to mTOR inhibition $[2,7]$. Nevertheless, the salient point is that the impact of mTORC1 inhibition on $\mathrm{T}$ cell protein synthesis is limited, selective and context dependent.

These studies highlight that it is important to look beyond mTORC1 signaling when trying to understand how antigen receptors and cytokines control protein synthesis during a $T$ cell immune response. One hypothesis is that T cell protein synthesis is also regulated by the serine/threonine kinases MNK1/MNK2, which phosphorylate elF4E at Ser209 within minutes of T cell activation [93]; this phosphorylation event selectively controls protein translation in fibroblasts [94]. However, Mnk1/Mnk2 deletion, which ablated elF4E Ser209 phosphorylation, failed to impact T cell activation, proliferation, or effector cell differentiation, with only specific effects on cytokine production in an in vivo setting [93]. These results thus highlight that many textbook regulators of mRNA translation play only a selective role in regulating protein production in T cells. As discussed previously, a key switch that reproducibly regulates $T$ cell protein synthesis is the antigen and cytokine receptor control of MYC, which drives the expression of amino acid transporters to supply the key building blocks for protein synthesis. Whether there are other critical intracellular signaling molecules that couple the TCR and cytokines, such as IL2, to global control of mRNA translation remains largely unclear.

\section{HOW PROTEIN DEGRADATION CHANGES DURING A T CELL IMMUNE RESPONSE}

Howden et al. analyzed how $\mathrm{T}$ cell activation shapes $\mathrm{T}$ cell proteomes and estimated that $\sim 7-9 \%$ of $T$ cell proteins are downregulated as T cells respond to antigen [2]. Proteins whose expression decreases after immune activation include cell cycle inhibitors, transcription factors, and translational repressors. This controlled destruction of proteins that maintain $T$ cell quiescence is essential for T cell activation. Moreover, the balanced activities of protein synthesis and protein degradation are critical for maintaining protein expression levels throughout $T$ cell differentiation. The major pathways by which cellular proteins are degraded include the ubiquitin-proteasome pathway and lysosomal proteolysis during autophagy or endocytosis.

\section{Proteasomal degradation}

Proteins are targeted for proteasomal degradation when they are tagged with a polyubiquitin chain by ubiquitin ligases. Polyubiquitinated proteins are shuttled to the proteasome, where regulatory cap subunits recognize the protein, deubiquitinate it, and unfold it in preparation for proteolytic degradation by the protease activity of the proteasome core subunit proteins [95]. This process is important for T cell protein homeostasis, and the inhibition of proteasome activity results in large-scale cell death [96-98]. Proteasome activity can be regulated by proteasome quantity and composition, posttranslational modifications and the expression of proteasomal activators [95]. The extent to which each of these factors is relevant in T cells during an immune response is not well understood.

$T$ cells predominantly express a specialized form of the proteasome dubbed the "immunoproteasome", which differs by several subunits from the proteasome in most nonimmune cell types $[95,99]$. T cell activation proteomics datasets have revealed a coordinated increase in proteasomal protein expression, scaling with cell growth from $\sim 12$ to $24 \mathrm{~h}$ post activation $[2,6,7]$. Proteasome protein levels are maintained or increased further in in vitro-generated effector CD8 and CD4 T cell subsets $[2,7]$. Examination of proteomics data from proliferating $T$ cells during an in vivo infection showed moderately higher expression of a number of proteasome subunits relative to naive $T$ cells on the same day [36]. A study measuring the proteolytic activity of purified proteasomes of naive versus $48 \mathrm{~h}$ in vitro-activated T cells showed an increase in proteolytic enzyme activity upon $\mathrm{T}$ cell activation [100], consistent with the increase in proteasome expression. Another study using an activity-based fluorescent probe for detecting proteasomal subunits in intact live cells showed that dividing in vivo CD8 $T$ cells responding to ListeriaOVA had high proteasomal activity if they had a memory precursor (CD62LhiCD25lo) phenotype and lower proteasomal activity if they had an effector precursor (CD62LloCD25hi) phenotype at 2.5 days post infection [101]. How this early postactivation activity differs relative to that of naive $T$ cells was not measured; however, the researchers noted that naive $T$ cells and terminal effector CD8 $\mathrm{T}$ cells had equivalent proteasomal activity [101]. The molecular impact of changes in proteasome levels and activity in effector T cells is not fully understood, but proteasome control of the expression of TBET, a key transcription factor for T cell effector differentiation, has been proposed [102]. It has also been shown that $T$ cells deficient for the immunoproteasome-specialized subunit LMP7 fail to normally differentiate into effector cells [103].

Is there immune control of proteasomal protein degradation pathways in T cells? One obvious point of control is the phosphorylation of some proteins in immune-activated $T$ cells (e.g., the transcription factor MYC and the translational repressor PDCD4) that targets these proteins for ubiquitination and degradation (Fig. 3) $[6,63$, 83]. It may also be pertinent that multiple posttranslational modifications have been reported to modulate proteasome activity, including phosphorylation, polyADP ribosylation, methylation, acetylation, and S-glutathionylation [95]. There is also biochemical evidence for antigen receptor- and IL2-regulated phosphorylation of proteasome subunits $[6,38]$, but whether these are functionally meaningful in T cells is not known. Indeed, the role of posttranslational modifications of the proteasome subunit in shaping proteasome activity in T cells is largely unexplored, with the exception that there is some understanding of the regulation and function of the E3 ubiquitin ligases that ubiquitinate and target proteins to the proteasome for degradation. This targeted degradation is important for shaping the overall proteome, triggering and dampening cell signaling, and destroying unwanted proteins, which is important for maintaining or rapidly changing $T$ cell fate. The specific targets of E3 ubiquitin ligases and how they control T cell differentiation are beyond the scope of this review, and we refer readers to several good reviews on these topics [104, 105].

\section{Lysosomal proteolysis-autophagy}

The other major mechanism by which proteins are degraded is lysosomal proteolysis, wherein lysosomal fusion with other vesicles allows lysosomal hydrolases to destroy the contents of the vesicle. This process occurs either via endocytosis, whereby the plasma membrane and extracellular proteins are internalized, or via autophagy, whereby cytoplasmic proteins and organelles become encompassed by a double membrane structure called the autophagosome, which fuses with the lysosome [106-108]. For the purposes of this review, we will focus on lysosomal degradation by autophagy, as this process functions to provide amino acids to fuel protein synthesis. Over recent years, it has become evident that autophagy is important for shaping $\mathrm{T}$ cell 
immunity, although the literature is somewhat conflicting regarding when autophagy occurs in $\mathrm{T}$ cells and exactly how it is regulated at different stages of the $T$ cell response [106-108]. However, there is a consensus that autophagy is important for generating and maintaining memory CD4 and CD8 T cells. Multiple studies using genetic deletions of important autophagy proteins (ATG5 and ATG7) have revealed defects in memory cell numbers and recall responses [109-112]. Furthermore, autophagy is critical for naive T cell survival; studies using conditional genetic deletion of autophagy proteins (VPS34, ATG3, ATG5, and ATG7) showed reduced peripheral naive $T$ cell numbers, which were attributed to a failure to remove damaged mitochondria [113115] [109, 116]. In human naive and memory CD4 T cells, proteomic studies have found that the autophagy cargo receptor SQSTM1 is one of the most rapidly turned over proteins [7]. When naive $T$ cell protein synthesis was inhibited, proteasomal inhibition did not rescue the loss of SQSTM1 expression, supporting the idea that autophagy occurs in these cells. Not all of the proteins that were turned over in a proteasome-independent manner were mitochondrial [7], providing clues as to other targets of autophagy in naive $T$ cells.

Examinations of $\mathrm{T}$ cell proteomes have shown a net increase in components of the autophagy pathway after $24 \mathrm{~h}$ of $\mathrm{T}$ cell activation $[2,7]$. Several studies have monitored the expression of lipidated LC3B, a key protein involved in autophagy substrate selection, and reported increases in autophagic vesicle expression upon TCR activation and effector differentiation [117-119]. This increase in autophagy-mediating proteins in activated $T$ cells could correspond with an enhanced capability for autophagy but could also indicate that autophagic flux is reduced and proteins are no longer being destroyed. More accurate monitoring of autophagic flux in T cells over the course of an in vivo LCMV infection suggested that autophagy was reduced in activated $T$ cells [112]. The precise timing of autophagy regulation in T cells is thus somewhat controversial, reflecting the difficulty in interpreting autophagy assays [120]. Nevertheless, it is evident that dynamic changes in autophagy do occur during $T$ cell activation and that autophagy is important for $\mathrm{T}$ cell participation in adaptive immune responses.

\section{T CELL ENERGY METABOLISM-WHAT HAVE WE LEARNED FROM PROTEOMICS STUDIES?}

Following antigen receptor engagement, very fast changes occur in multiple cellular metabolism pathways. Activated $\mathrm{T}$ cells increase glycolysis and mitochondrial OXPHOS to produce ATP while decreasing mitochondrial fatty acid oxidation (FAO) $[36,43,62]$. How T cells control glucose and fatty acid metabolism over the course of an immune response has been extensively reviewed [121-123]. Here, we will briefly summarize how $T$ cell glucose metabolism changes during immune activation (illustrated in Fig. 2), incorporating new insights from high-resolution mass spectrometry before discussing crosstalk between glucose metabolism and protein synthesis and degradation.

The increase in the $\mathrm{T}$ cell glycolytic rate is relatively rapid, detectable within a few minutes of TCR stimulation, and this rate continues to increase over hours of immune activation [62, 124]. Naive T cells already contain a large amount of glycolytic enzymes $[2,3,7]$, but the expression of most glycolytic enzymes increases after $\sim 8-12 \mathrm{~h}$ of immune activation [5-7]. One rate-limiting step in glycolysis is glucose supply $[33,125,126]$. The glucose transport capacity of naive T cells is very low $[69,80,127]$, but increases in glucose transport capability have been detected within $2 \mathrm{~h}$ of $\mathrm{T}$ cell activation (Linda V. Sinclair, personal communication), and high levels of glucose transport have been detected in effector cells $[33,69,80,127]$. The sustained increase in the glucose transport capacity of immune-activated $T$ cells is mediated by increased glucose transporter expression. T cells express two glucose transporters, GLUT1 (SLC2A1) and GLUT3 (SLC2A3). The expression of these proteins is very low in naive $T$ cells but high in antigen-activated and effector $T$ cells $[1-3,7,33]$. Studies have typically not measured a net increase in total glucose transporter expression levels until 8-12 h post TCR stimulation [6, 7]; however, it is proposed that glucose transporters shuttle from intracellular vesicles to the cell surface during $T$ cell activation [125]. In this context, it was recently noted that the protein TXNIP, which drives glucose transporter endocytosis, is rapidly destroyed upon $T$ cell activation [6, 7]; this process could regulate early glucose uptake. However, glucose import and lactate export must both increase for increased glycolytic flux. It is thus striking that immuneactivated $T$ cells rapidly increase the expression of the lactate exporters MCT1 (SLC16A1) and MCT4 (SLC16A3) [6, 7].

Increased mitochondrial OXPHOS has also been measured within hours of $T$ cell activation [5] and has been shown to increase as $T$ cells activate and differentiate [36, 43]. These changes in $\mathrm{T}$ cell metabolism are supported by dramatic mitochondrial remodeling and mitochondrial biogenesis $[5,6]$. Mitochondria number and protein content do not increase within the first few hours of T cell activation but gradually increase from $\sim 9 \mathrm{~h}$ onwards [5]. In addition to glucose, OXPHOS can be fueled by amino acids such as glutamine during $T$ cell activation [62]. Glutamine transporter expression increases during early $\mathrm{T}$ cell activation [3] and may contribute to the early increase in OXPHOS observed in T cells. Mitochondrial protein content does not scale with only mitochondrial number or total cell size upon $\mathrm{T}$ cell activation; mitochondrial proteins make up a higher percentage of the total cellular protein content at $24 \mathrm{~h}$ in in vitro immuneactivated and effector T cells than in naive T cells [2]. Furthermore, select mitochondrial proteins, such as those involved in onecarbon metabolism, which generates metabolites for de novo purine biosynthesis and controls glutathione levels, are rapidly and disproportionately increased compared to other mitochondrial components [5].

\section{CROSSTALK BETWEEN GLUCOSE METABOLISM AND PROTEIN SYNTHESIS AND DEGRADATION}

Protein synthesis is a metabolically demanding process. It has been estimated that $\sim 5$ ATP per peptide bond or $\sim 2300$ ATP per typical protein synthesized are required [10]. This requirement equates to the energy from $\sim 1100$ molecules of glucose processed through glycolysis or $\sim 60-70$ molecules of glucose for OXPHOS if these processes were $100 \%$ efficient. The intrinsic link between ATP production and protein synthesis was demonstrated in an elegant technology paper by Arguello et al., who exploited the ATP dependence of protein synthesis to measure the metabolic profile of single cells [128]. In this study, protein synthesis in T cells was assayed using a single flow cytometry assay that quantifies the incorporation of a puromycin analog into nascent protein chains in the ribosome. This enabled the use of inhibitors of either glycolysis or oxidative phosphorylation to assess the contribution of ATP produced by either pathway to protein production. This work showed that the inhibition of energy metabolism across all T cell differentiation states caused a strong decrease in protein synthesis, and the authors concluded that protein synthesis in TCR-activated and effector T cells was more dependent on glycolysis, whereas oxidative phosphorylation was more important for driving protein synthesis in naive and memory $T$ cells.

Autophagy can be triggered by nutrient deprivation in multiple cell types. Protein degradation via autophagy generates more resources and energy than are utilized in the process [54]. Very little is known about crosstalk between energy metabolism and autophagy in $\mathrm{T}$ cells, although several studies have noted that a decrease in autophagy is linked to an increase in glycolysis [129131] and have implicated glycolytic enzymes as potential targets of autophagy [130]. Whether these data imply a mechanism by 
which environmental nutrient stress feeds back to dampen metabolic pathways that support high levels of biosynthesis in $\mathrm{T}$ cells requires further study. Protein degradation via the proteasome is a net consumer of ATP, although the amount as a proportion of the total cellular energy usage is thought to be relatively small [10]. In cultured neurons, inhibition of complex I of the electron transport chain reduced proteasome activity [132], but the extent to which a reduction in ATP inhibits proteasomal activity in T cells is unclear. There is, however, evidence that protein degradation via the proteasome can feedback to control cellular metabolism in T cells. For example, treatment of activated CD8 $T$ cells with a proteasome inhibitor increased glycolysis, whereas $\mathrm{T}$ cells treated with a proteasome activator showed decreased glycolysis [101]. One explanation for this phenomenon is that the expression of glucose transporters, lactate transporters, and glycolytic enzymes in T cells is controlled by the transcription factor HIF1a [80]. HIF1a has a very short half-life in effector T cells because it is ubiquitinated by the VHL-containing ubiquitin ligase complex and then targeted for proteasomal degradation. Proteosome inhibition would thus increase the expression of HIF1a, which is known to drive glycolysis in effector T cells [80]. Changes in proteasome activity could also regulate the expression of MYC, another transcription factor that controls $\mathrm{T}$ cell metabolism $[3,62]$. In T cells, MYC has a short half-life because it can be rapidly degraded by the proteasome. A reduction in proteasomal activity thus substantially increases MYC expression [63]. Moreover, as illustrated in Fig. 3, the expression of MYC is an interesting example of how the nutrient environment can shape the expression of a protein by balancing protein synthesis and degradation. MYC degradation is controlled by phosphorylation at Thr58, which helps recruit ubiquitin ligases, hence targeting MYC for proteasomal degradation [63]. However, MYC can be O-GlcNAcylated at Thr58, which prevents Thr58 phosphorylation and MYC degradation, allowing this transcription factor to accumulate. The rate of MYC O-GlcNAcylation is controlled by the supply of glutamine and glucose, which are metabolized via the hexosamine biosynthetic pathway to produce UDP-GICNAc, the donor substrate for O-GlcNAc transferase, which catalyzes the addition of O-linked- $\mathrm{B}-\mathrm{N}$-acetylglucosamine (O-GIcNAc) to MYC Th58 [69]. Thus, a drop in either glucose or glutamine availability results in reduced MYC GlcNAcylation, the subsequent loss of MYC expression and, consequently, the loss of expression of key MYCcontrolled metabolic proteins. In this context, and as previously discussed, MYC-controlled expression of amino acid transporters is an essential switch for controlling protein production.

\section{CONCLUSION}

The precise regulation of protein synthesis and degradation shapes the functional capabilities of $T$ cell immune responses. Technological advances have revealed the constant dynamic turnover of proteins in both naive and effector $T$ cells and the balance between protein synthesis and degradation that is key for controlling protein expression. There have also been major advances in identifying some crucial checkpoints for $\mathrm{T}$ cell protein synthesis, including the importance of the regulation of amino acid transporter expression and immune control of ATP production. There is, however, more to learn, particularly about how diet and competition with other cells shape nutrient availability to $\mathrm{T}$ cells and how signaling molecules and environmental nutrients selectively impact $T$ cell protein expression. Understanding how $T$ cells prioritize protein production and which proteins they will degrade under conditions of energy and nutrient stress will be of particular value for efforts to refine anticancer $T$ cell therapies and develop $T$ cell tissue-targeted therapies for inflammatory disease progression. However, there are now sensitive and quantitative technologies for measuring protein synthesis and $\mathrm{T}$ cell proteomes that will facilitate our understanding of these key issues.

\section{REFERENCES}

1. Damasio MP, Marchingo JM, Spinelli L, Hukelmann JL, Cantrell DA, Howden AJM. Extracellular signal-regulated kinase (ERK) pathway control of CD8+ T cell differentiation. Biochem J. 2021;478:79-98.

2. Howden AJM, Hukelmann JL, Brenes A, Spinelli L, Sinclair LV, Lamond Al, et al. Quantitative analysis of $\mathrm{T}$ cell proteomes and environmental sensors during $\mathrm{T}$ cell differentiation. Nature Immunology. 2019;20:1542-54.

3. Marchingo JM, Sinclair LV, Howden AJ, Cantrell DA. Quantitative analysis of how Myc controls $T$ cell proteomes and metabolic pathways during T cell activation. Elife. 2020;9:e53725.

4. Marchingo JM, Kan A, Sutherland RM, Duffy KR, Wellard CJ, Belz GT, et al. T cell signaling. Antigen affinity, costimulation, and cytokine inputs sum linearly to amplify T cell expansion. Science. 2014;346:1123-7.

5. Ron-Harel N, Santos D, Ghergurovich JM, Sage PT, Reddy A, Lovitch SB, et al. Mitochondrial biogenesis and proteome remodeling promote one-carbon metabolism for T cell activation. Cell Metab. 2016;24:104-17.

6. Tan H, Yang K, Li Y, Shaw Tl, Wang Y, Blanco DB, et al. Integrative proteomics and phosphoproteomics profiling reveals dynamic signaling networks and bioenergetics pathways underlying T cell activation. Immunity 2017;46:488-503.

7. Wolf T, Jin W, Zoppi G, Vogel IA, Akhmedov M, Bleck CKE, et al. Dynamics in protein translation sustaining T cell preparedness. Nat Immunol. 2020;21:927-37.

8. Buttgereit F, Brand MD. A hierarchy of ATP-consuming processes in mammalian cells. Biochem J. 1995:312:163-7.

9. Hosios AM, Hecht VC, Danai LV, Johnson MO, Rathmell JC, Steinhauser ML, et al. Amino acids rather than glucose account for the majority of cell mass in proliferating mammalian cells. Dev Cell. 2016;36:540-9.

10. Princiotta MF, Finzi D, Qian SB, Gibbs J, Schuchmann S, Buttgereit F, et al. Quantitating protein synthesis, degradation, and endogenous antigen processing. Immunity 2003;18:343-54.

11. Hershey JWB, Sonenberg N, Mathews MB. Principles of translational control. Cold Spring Harb Perspect Biol. 2019;11:a032607.

12. Merrick WC, Pavitt GD. Protein Synthesis Initiation in Eukaryotic Cells. Cold Spring Harb Perspect Biol. 2018;10:a033092.

13. Piccirillo CA, Bjur E, Topisirovic I, Sonenberg N, Larsson O. Translational control of immune responses: from transcripts to translatomes. Nat Immunol. 2014;15:503-11.

14. Curdy N, Lanvin O, Cadot S, Laurent C, Fournie JJ, Franchini DM. Stress granules in the post-transcriptional regulation of immune cells. Front Cell Dev Biol. 2020;8:611185.

15. Galloway A, Cowling VH. mRNA cap regulation in mammalian cell function and fate. Biochim Biophys Acta Gene Regul Mech. 2019;1862:270-9.

16. Araki K, Morita M, Bederman AG, Konieczny BT, Kissick HT, Sonenberg N, et al. Translation is actively regulated during the differentiation of CD8(+) effector T cells. Nat Immunol. 2017;18:1046-57.

17. Ricciardi S, Manfrini N, Alfieri R, Calamita P, Crosti MC, Gallo S, et al. The Translational Machinery of Human CD4(+) T Cells Is Poised for Activation and Controls the Switch from Quiescence to Metabolic Remodeling. Cell Metab. 2018;28:961.

18. Sinclair LV, Howden AJ, Brenes A, Spinelli L, Hukelmann JL, Macintyre AN, et al. Antigen receptor control of methionine metabolism in T cells. Elife. 2019;8:e44210.

19. Myers DR, Wheeler B, Roose JP. mTOR and other effector kinase signals that impact T cell function and activity. Immunol Rev. 2019;291:134-53.

20. Bennett TJ, Udupa VAV, Turner SJ. Running to Stand Still: Naive CD8(+) T Cells Actively Maintain a Program of Quiescence. Int J Mol Sci. 2020;21:9773.

21. Delpoux A, Marcel N, Hess Michelini R, Katayama CD, Allison KA, Glass CK, et al. FOXO1 constrains activation and regulates senescence in CD8 T cells. Cell Rep. 2021;34:108674.

22. Bjur E, Larsson O, Yurchenko E, Zheng L, Gandin V, Topisirovic I, et al. Distinct translational control in CD4+ T cell subsets. PLoS Genet. 2013;9:e1003494.

23. Tan TCJ, Knight J, Sbarrato T, Dudek K, Willis AE, Zamoyska R. Suboptimal T-cell receptor signaling compromises protein translation, ribosome biogenesis, and proliferation of mouse CD8 T cells. Proc Natl Acad Sci USA. 2017;114:E6117-E26.

24. Biever A, Glock C, Tushev G, Ciirdaeva E, Dalmay T, Langer JD, et al. Monosomes actively translate synaptic mRNAs in neuronal processes. Science. 2020;367: eaay4991.

25. Heyer EE, Moore MJ. Redefining the Translational Status of $80 \mathrm{~S}$ Monosomes. Cell. 2016;164:757-69.

26. Nowell PC. Phytohemagglutinin: an initiator of mitosis in cultures of normal human leukocytes. Cancer Res. 1960;20:462-6.

27. Mao X, Green JM, Safer B, Lindsten T, Frederickson RM, Miyamoto S, et al. Regulation of translation initiation factor gene expression during human $T$ cell activation. J Biol Chem. 1992;267:20444-50.

28. Best JA, Blair DA, Knell J, Yang E, Mayya V, Doedens A, et al. Transcriptional insights into the $\mathrm{CD} 8(+) \mathrm{T}$ cell response to infection and memory $\mathrm{T}$ cell formation. Nat Immunol. 2013;14:404-12. 
29. Marchingo JM, Cantrell DA. The active inner life of naive T cells. Nat Immunol. 2020;21:827-8

30. Richard AC, Lun ATL, Lau WWY, Gottgens B, Marioni JC, Griffiths GM. T cell cytolytic capacity is independent of initial stimulation strength. Nat Immunol. 2018;19:849-58.

31. Spinelli L, Marchingo JM, Nomura A, Damasio MP, Cantrell DA. Phosphoinositide 3-Kinase p110 Delta Differentially Restrains and Directs Naive Versus Effector CD8(+) T Cell Transcriptional Programs. Front Immunol. 2021;12:691997.

32. Galloway A, Kaskar A, Ditsova D, Atrih A, Yoshikawa H, Gomez-Moreira C, et al. Upregulation of RNA cap methyltransferase RNMT drives ribosome biogenesis during T cell activation. Nucleic Acids Res. 2021;49:6722-38.

33. Hukelmann JL, Anderson KE, Sinclair LV, Grzes KM, Murillo AB, Hawkins PT, et al. The cytotoxic $T$ cell proteome and its shaping by the kinase mTOR. Nat Immunol. 2016;17:104-12.

34. Buccitelli $C$, Selbach M. mRNAs, proteins and the emerging principles of gene expression control. Nat Rev Genet. 2020;21:630-44.

35. Liu Y, Beyer A, Aebersold R. On the dependency of cellular protein levels on mRNA abundance. Cell. 2016;165:535-50.

36. Ma EH, Verway MJ, Johnson RM, Roy DG, Steadman M, Hayes S, et al. Metabolic profiling using stable isotope tracing reveals distinct patterns of glucose utilization by physiologically activated CD8(+) T cells. Immunity. 2019;51:856-70.

37. Rollings CM, Sinclair LV, Brady HJM, Cantrell DA, Ross SH. Interleukin-2 shapes the cytotoxic $\mathrm{T}$ cell proteome and immune environment-sensing programs. Sci Signal. 2018;11.

38. Ross SH, Rollings C, Anderson KE, Hawkins PT, Stephens LR, Cantrell DA. Phosphoproteomic analyses of interleukin 2 signaling reveal integrated JAK kinasedependent and -independent networks in $\mathrm{CD} 8(+) \mathrm{T}$ cells. Immunity. 2016;45:685-700.

39. Cantrell DA, Smith KA. The interleukin-2 T-cell system: a new cell growth model. Science. 1984;224:1312-6.

40. Cornish GH, Sinclair LV, Cantrell DA. Differential regulation of T-cell growth by IL2 and IL-15. Blood. 2006;108:600-8.

41. Weninger W, Crowley MA, Manjunath N, von Andrian UH. Migratory properties of naive, effector, and memory CD8(+) T cells. J Exp Med. 2001;194:953-66.

42. Rieckmann JC, Geiger R, Hornburg D, Wolf T, Kveler K, Jarrossay D, et al. Social network architecture of human immune cells unveiled by quantitative proteomics. Nat Immunol. 2017;18:583-93.

43. Chang $\mathrm{CH}$, Curtis JD, Maggi LB Jr., Faubert B, Villarino AV, O'Sullivan D, et al. Posttranscriptional control of T cell effector function by aerobic glycolysis. Cell. 2013;153:1239-51.

44. Salerno F, Engels S, van den Biggelaar M, van Alphen FPJ, Guislain A, Zhao W, et al. Translational repression of pre-formed cytokine-encoding mRNA prevents chronic activation of memory T cells. Nat Immunol. 2018;19:828-37.

45. Villarino AV, Katzman SD, Gallo E, Miller O, Jiang S, McManus MT, et al. Posttranscriptional silencing of effector cytokine mRNA underlies the anergic phenotype of self-reactive T cells. Immunity. 2011;34:50-60.

46. Ben-Asouli $Y$, Banai $Y$, Pel-Or Y, Shir A, Kaempfer R. Human interferon-gamma mRNA autoregulates its translation through a pseudoknot that activates the interferon-inducible protein kinase PKR. Cell. 2002;108:221-32.

47. Hilliard A, Hilliard B, Zheng SJ, Sun H, Miwa T, Song W, et al. Translational regulation of autoimmune inflammation and lymphoma genesis by programmed cell death 4. J Immunol. 2006;177:8095-102.

48. Salerno F, Paolini NA, Stark R, von Lindern M, Wolkers MC. Distinct PKCmediated posttranscriptional events set cytokine production kinetics in CD8(+) T cells. Proc Natl Acad Sci USA. 2017;114:9677-82.

49. Scheu S, Stetson DB, Reinhardt RL, Leber JH, Mohrs M, Locksley RM. Activation of the integrated stress response during $T$ helper cell differentiation. Nat Immunol. 2006;7:644-51.

50. Nakaya $M$, Xiao $Y$, Zhou $X$, Chang JH, Chang $M$, Cheng $X$, et al. Inflammatory $T$ cell responses rely on amino acid transporter ASCT2 facilitation of glutamine uptake and mTORC1 kinase activation. Immunity. 2014;40:692-705.

51. Sinclair LV, Rolf J, Emslie E, Shi YB, Taylor PM, Cantrell DA. Control of amino-acid transport by antigen receptors coordinates the metabolic reprogramming essential for T cell differentiation. Nat Immunol. 2013;14:500-8.

52. Charpentier JC, Chen D, Lapinski PE, Turner J, Grigorova I, Swanson JA, et al. Macropinocytosis drives T cell growth by sustaining the activation of mTORC1. Nat Commun. 2020;11:180.

53. Hope HC, Brownlie RJ, Fife CM, Steele L, Lorger M, Salmond RJ. Coordination of asparagine uptake and asparagine synthetase expression modulates CD8 $+\mathrm{T}$ cell activation. JCI Insight. 2021;6.

54. Singh R, Cuervo AM. Autophagy in the cellular energetic balance. Cell Metab. 2011;13:495-504.

55. Roy DG, Chen J, Mamane V, Ma EH, Muhire BM, Sheldon RD, et al. Methionine metabolism shapes $T$ helper cell responses through regulation of epigenetic reprogramming. Cell Metab. 2020;31:250-66 e9.
56. Bian Y, Li W, Kremer DM, Sajjakulnukit P, Li S, Crespo J, et al. Cancer SLC43A2 alters $T$ cell methionine metabolism and histone methylation. Nature. 2020;585:277-82.

57. Murray PJ. Amino acid auxotrophy as a system of immunological control nodes. Nat Immunol. 2016;17:132-9.

58. Geiger R, Rieckmann JC, Wolf T, Basso C, Feng Y, Fuhrer T, et al. L-arginine modulates $T$ cell metabolism and enhances survival and anti-tumor activity. Cell. 2016;167:829-42 e13.

59. Sinclair LV, Neyens D, Ramsay G, Taylor PM, Cantrell DA. Single cell analysis of kynurenine and System $\mathrm{L}$ amino acid transport in $\mathrm{T}$ cells. Nat Commun. 2018;9:1981.

60. Grumont R, Lock P, Mollinari M, Shannon FM, Moore A, Gerondakis S. The mitogen-induced increase in T cell size involves PKC and NFAT activation of Rel/ NF-kappaB-dependent c-myc expression. Immunity. 2004;21:19-30.

61. Mak TW, Grusdat M, Duncan GS, Dostert C, Nonnenmacher $Y$, Cox M, et al. Glutathione primes $T$ cell metabolism for inflammation. Immunity. 2017;46:1089-90.

62. Wang R, Dillon CP, Shi LZ, Milasta S, Carter R, Finkelstein D, et al. The transcription factor Myc controls metabolic reprogramming upon $T$ lymphocyte activation. Immunity. 2011;35:871-82.

63. Preston GC, Sinclair LV, Kaskar A, Hukelmann JL, Navarro MN, Ferrero I, et al. Single cell tuning of Myc expression by antigen receptor signal strength and interleukin-2 in T lymphocytes. EMBO J. 2015;34:2008-24.

64. Carr EL, Kelman A, Wu GS, Gopaul R, Senkevitch E, Aghvanyan A, et al. Glutamine uptake and metabolism are coordinately regulated by ERK/MAPK during $T$ lymphocyte activation. J Immunol. 2010;185:1037-44.

65. Rodriguez PC, Hernandez CP, Morrow K, Sierra R, Zabaleta J, Wyczechowska DD, et al. L-arginine deprivation regulates cyclin D3 mRNA stability in human T cells by controlling HuR expression. J Immunol. 2010;185:5198-204.

66. Rodriguez PC, Quiceno DG, Ochoa AC. L-arginine availability regulates T-lymphocyte cell-cycle progression. Blood. 2007;109:1568-73.

67. Ron-Harel N, Ghergurovich JM, Notarangelo G, LaFleur MW, Tsubosaka Y, Sharpe $\mathrm{AH}$, et al. $\mathrm{T}$ cell activation depends on extracellular alanine. Cell Rep. 2019;28:3011-21 e4.

68. Wu J, Li G, Li L, Li D, Dong Z, Jiang P. Asparagine enhances LCK signalling to potentiate $\mathrm{CD} 8(+) \mathrm{T}$-cell activation and anti-tumour responses. Nat Cell Biol. 2021;23:75-86.

69. Swamy M, Pathak S, Grzes KM, Damerow S, Sinclair LV, van Aalten DM, et al. Glucose and glutamine fuel protein O-GIcNAcylation to control T cell selfrenewal and malignancy. Nat Immunol. 2016;17:712-20.

70. Johnson MO, Wolf MM, Madden MZ, Andrejeva G, Sugiura A, Contreras DC, et al. Distinct regulation of Th17 and Th1 cell differentiation by glutaminasedependent metabolism. Cell. 2018;175:1780-95 e19.

71. Leone RD, Zhao L, Englert JM, Sun IM, Oh MH, Sun IH, et al. Glutamine blockade induces divergent metabolic programs to overcome tumor immune evasion. Science. 2019;366:1013-21.

72. Castilho BA, Shanmugam R, Silva RC, Ramesh R, Himme BM, Sattlegger E. Keeping the elF2 alpha kinase Gcn2 in check. Biochim Biophys Acta. 2014;1843:1948-68.

73. Pavlova NN, King B, Josselsohn RH, Violante S, Macera VL, Vardhana SA, et al. Translation in amino-acid-poor environments is limited by tRNA(GIn) charging. Elife. 2020;9.

74. Rashidi A, Miska J, Lee-Chang C, Kanojia D, Panek WK, Lopez-Rosas A, et al. GCN2 is essential for CD8(+) T cell survival and function in murine models of malignant glioma. Cancer Immunol Immunother. 2020;69:81-94.

75. Van de Velde LA, Guo XJ, Barbaric L, Smith AM, Oguin TH 3rd, Thomas PG, et al. Stress kinase GCN2 controls the proliferative fitness and trafficking of cytotoxic $\mathrm{T}$ cells independent of environmental amino acid sensing. Cell Rep. 2016;17:2247-58.

76. Yue T, Zhan X, Zhang D, Jain R, Wang KW, Choi JH, et al. SLFN2 protection of tRNAs from stress-induced cleavage is essential for T cell-mediated immunity. Science. 2021;372.

77. Pollizzi KN, Powell JD. Regulation of T cells by mTOR: the known knowns and the known unknowns. Trends Immunol. 2015;36:13-20.

78. Shi H, Chapman NM, Wen J, Guy C, Long L, Dhungana $Y$, et al. Amino Acids License Kinase mTORC1 Activity and Treg Cell Function via Small G Proteins Rag and Rheb. Immunity. 2019;51:1012-27 e7.

79. So L, Lee J, Palafox M, Mallya S, Woxland CG, Arguello M, et al. The 4E-BP-elF4E axis promotes rapamycin-sensitive growth and proliferation in lymphocytes. Sci Signal. 2016:9:ra57.

80. Finlay DK, Rosenzweig E, Sinclair LV, Feijoo-Carnero C, Hukelmann JL, Rolf J, et al. PDK1 regulation of mTOR and hypoxia-inducible factor 1 integrate metabolism and migration of CD8+ T cells. J Exp Med. 2012;209:2441-53.

81. Zhang L. elF4E-dependent translational control of gene expression in CD4+ T cell subsets. https://escholarship.mcgill.ca: McGill University; 2012. 
82. Suzuki C, Garces RG, Edmonds KA, Hiller S, Hyberts SG, Marintchev A, et al. PDCD4 inhibits translation initiation by binding to elF4A using both its MA3 domains. Proc Natl Acad Sci USA. 2008;105:3274-9.

83. Dorrello NV, Peschiaroli A, Guardavaccaro D, Colburn NH, Sherman NE, Pagano M. S6K1- and betaTRCP-mediated degradation of PDCD4 promotes protein translation and cell growth. Science. 2006;314:467-71.

84. Lingel H, Wissing J, Arra A, Schanze D, Lienenklaus S, Klawonn F, et al. CTLA-4mediated posttranslational modifications direct cytotoxic T-lymphocyte differentiation. Cell Death Differ. 2017;24:1739-49.

85. Fingar DC, Salama S, Tsou C, Harlow E, Blenis J. Mammalian cell size is controlled by mTOR and its downstream targets S6K1 and 4EBP1/elF4E. Genes Dev. 2002;16:1472-87.

86. Laplante M, Sabatini DM. mTOR signaling in growth control and disease. Cell. 2012;149:274-93.

87. Loewith $\mathrm{R}$, Hall MN. Target of rapamycin (TOR) in nutrient signaling and growth control. Genetics. 2011;189:1177-201.

88. Sinclair LV, Finlay D, Feijoo C, Cornish GH, Gray A, Ager A, et al. Phosphatidylinositol-3-OH kinase and nutrient-sensing mTOR pathways control T lymphocyte trafficking. Nat Immunol. 2008;9:513-21.

89. Shahbazian D, Roux PP, Mieulet V, Cohen MS, Raught B, Taunton J, et al. The mTOR/PI3K and MAPK pathways converge on elF4B to control its phosphorylation and activity. EMBO J. 2006;25:2781-91.

90. Salmond RJ, Brownlie RJ, Meyuhas O, Zamoyska R. Mechanistic target of rapamycin complex 1/S6 kinase 1 signals influence T cell activation independently of ribosomal protein S6 phosphorylation. J Immunol. 2015;195:4615-22.

91. Salmond RJ, Emery J, Okkenhaug K, Zamoyska R. MAPK, phosphatidylinositol 3kinase, and mammalian target of rapamycin pathways converge at the level of ribosomal protein S6 phosphorylation to control metabolic signaling in CD8 T cells. J Immunol. 2009;183:7388-97.

92. Ruvinsky I, Sharon N, Lerer T, Cohen H, Stolovich-Rain M, Nir T, et al. Ribosomal protein $\mathrm{S} 6$ phosphorylation is a determinant of cell size and glucose homeostasis. Genes Dev. 2005;19:2199-211.

93. Gorentla BK, Krishna S, Shin J, Inoue M, Shinohara ML, Grayson JM, et al. Mnk1 and 2 are dispensable for $T$ cell development and activation but important for the pathogenesis of experimental autoimmune encephalomyelitis. J Immunol. 2013;190:1026-37.

94. Furic L, Rong L, Larsson O, Koumakpayi IH, Yoshida K, Brueschke A, et al. elF4E phosphorylation promotes tumorigenesis and is associated with prostate cancer progression. Proc Natl Acad Sci USA. 2010;107:14134-9.

95. Kors S, Geijtenbeek K, Reits E, Schipper-Krom S. Regulation of proteasome activity by (post-)transcriptional mechanisms. Front Mol Biosci. 2019;6:48.

96. Berges C, Haberstock H, Fuchs D, Miltz M, Sadeghi M, Opelz G, et al. Proteasome inhibition suppresses essential immune functions of human CD4+ T cells. Immunology. 2008;124:234-46.

97. Berges C, Haberstock H, Fuchs D, Sadeghi M, Opelz G, Daniel V, et al. Proteasome inhibition activates the mitochondrial pathway of apoptosis in human CD4+ T cells. J Cell Biochem. 2009;108:935-46.

98. Wang $\mathrm{X}$, Luo $\mathrm{H}$, Chen $\mathrm{H}$, Duguid W, Wu J. Role of proteasomes in T cell activation and proliferation. J Immunol. 1998;160:788-801.

99. Murata S, Takahama Y, Kasahara M, Tanaka K. The immunoproteasome and thymoproteasome: functions, evolution and human disease. Nat Immunol. 2018;19:923-31.

100. Arata Y, Watanabe A, Motosugi R, Murakami R, Goto T, Hori S, et al. Defective induction of the proteasome associated with $\mathrm{T}$-cell receptor signaling underlies T-cell senescence. Genes Cells. 2019;24:801-13.

101. Widjaja CE, Olvera JG, Metz PJ, Phan AT, Savas JN, de Bruin G, et al. Proteasome activity regulates $\mathrm{CD} 8+\mathrm{T}$ lymphocyte metabolism and fate specification. J Clin Investig. 2017;127:3609-23.

102. Chang JT, Ciocca ML, Kinjyo I, Palanivel VR, McClurkin CE, Dejong CS, et al. Asymmetric proteasome segregation as a mechanism for unequal partitioning of the transcription factor T-bet during $\mathrm{T}$ lymphocyte division. Immunity. 2011;34:492-504.

103. Kalim KW, Basler M, Kirk CJ, Groettrup M. Immunoproteasome subunit LMP7 deficiency and inhibition suppresses Th1 and Th17 but enhances regulatory $T$ cell differentiation. J Immunol. 2012;189:4182-93.

104. $\mathrm{Hu} \mathrm{H}$, Sun SC. Ubiquitin signaling in immune responses. Cell Res. 2016;26:457-83.

105. Layman AA, Oliver PM. Ubiquitin ligases and deubiquitinating enzymes in CD4+ T cell effector fate choice and function. J Immunol. 2016;196:3975-82.

106. Macian F. Autophagy in T cell function and aging. Front Cell Dev Biol. 2019;7:213.

107. Merkley SD, Chock CJ, Yang XO, Harris J, Castillo EF. Modulating T cell responses via autophagy: the intrinsic influence controlling the function of both antigenpresenting cells and T cells. Front Immunol. 2018;9:2914.
108. Wang L, Das JK, Kumar A, Peng HY, Ren Y, Xiong X, et al. Autophagy in T-cell differentiation, survival and memory. Immunol Cell Biol. 2021;99:351-60.

109. Murera D, Arbogast F, Arnold J, Bouis D, Muller S, Gros F. CD4 T cell autophagy is integral to memory maintenance. Sci Rep. 2018;8:5951.

110. Puleston DJ, Zhang H, Powell TJ, Lipina E, Sims S, Panse I, et al. Autophagy is a critical regulator of memory CD8(+) T cell formation. Elife. 2014;3.

111. Schlie K, Westerback A, DeVorkin L, Hughson LR, Brandon JM, MacPherson S, et al. Survival of effector CD8 $+\mathrm{T}$ cells during influenza infection is dependent on autophagy. J Immunol. 2015;194:4277-86.

112. Xu X, Araki K, Li S, Han JH, Ye L, Tan WG, et al. Autophagy is essential for effector CD8(+) T cell survival and memory formation. Nat Immunol. 2014;15:1152-61.

113. Jia $W$, He YW. Temporal regulation of intracellular organelle homeostasis in $T$ lymphocytes by autophagy. J Immunol. 2011;186:5313-22.

114. Willinger T, Flavell RA. Canonical autophagy dependent on the class III phosphoinositide-3 kinase $\mathrm{Vps} 34$ is required for naive T-cell homeostasis. Proc Natl Acad Sci USA. 2012;109:8670-5.

115. Pua HH, Guo J, Komatsu M, He YW. Autophagy is essential for mitochondrial clearance in mature T lymphocytes. J Immunol. 2009;182:4046-55.

116. Parekh V, Wu L, Boyd KL, Williams JA, Gaddy JA, Olivares-Villagomez D, et al. Impaired autophagy, defective $T$ cell homeostasis, and a wasting syndrome in mice with a T cell-specific deletion of Vps34. J Immunol. 2013;190:5086-101.

117. Botbol Y, Patel B, Macian F. Common gamma-chain cytokine signaling is required for macroautophagy induction during CD4+ T-cell activation. Autophagy. 2015;11:1864-77.

118. Hubbard VM, Valdor R, Patel B, Singh R, Cuervo AM, Macian F. Macroautophagy regulates energy metabolism during effector $\mathrm{T}$ cell activation. J Immunol. 2010;185:7349-57.

119. Li C, Capan E, Zhao Y, Zhao J, Stolz D, Watkins SC, et al. Autophagy is induced in CD4+ T cells and important for the growth factor-withdrawal cell death. J Immunol. 2006;177:5163-8.

120. Klionsky DJ, Abdel-Aziz AK, Abdelfatah S, Abdellatif M, Abdoli A, Abel S, et al. Guidelines for the use and interpretation of assays for monitoring autophagy (4th edition)(1). Autophagy. 2021;17:1-382.

121. Geltink RIK, Kyle RL, Pearce EL. Unraveling the complex interplay between T cell metabolism and function. Annu Rev Immunol. 2018;36:461-88.

122. O'Neill LA, Kishton RJ, Rathmell J. A guide to immunometabolism for immunologists. Nat Rev Immunol. 2016;16:553-65.

123. Saravia J, Raynor JL, Chapman NM, Lim SA, Chi H. Signaling networks in immunometabolism. Cell Res. 2020;30:328-42.

124. Menk AV, Scharping NE, Moreci RS, Zeng X, Guy C, Salvatore S, et al. Early TCR signaling induces rapid aerobic glycolysis enabling distinct acute $T$ cell effector functions. Cell Rep. 2018;22:1509-21.

125. Macintyre AN, Gerriets VA, Nichols AG, Michalek RD, Rudolph MC, Deoliveira D, et al. The glucose transporter Glut1 is selectively essential for CD4 T cell activation and effector function. Cell Metab. 2014;20:61-72.

126. Tanner LB, Goglia AG, Wei MH, Sehgal T, Parsons LR, Park JO, et al. Four key steps control glycolytic flux in mammalian cells. Cell Syst. 2018;7:49-62.

127. Sinclair LV, Barthelemy C, Cantrell DA. Single cell glucose uptake assays: a cautionary tale. Immunometabolism. 2020;2:e200029.

128. Arguello RJ, Combes AJ, Char R, Gigan JP, Baaziz Al, Bousiquot E, et al. SCENITH: a flow cytometry-based method to functionally profile energy metabolism with single-cell resolution. Cell Metab. 2020;32:1063-75.

129. Wei J, Long L, Yang K, Guy C, Shrestha S, Chen Z, et al. Autophagy enforces functional integrity of regulatory $T$ cells by coupling environmental cues and metabolic homeostasis. Nat Immunol. 2016;17:277-85.

130. Gu M, Zhou X, Sohn JH, Zhu L, Jie Z, Yang JY, et al. NF-kappaB-inducing kinase maintains $T$ cell metabolic fitness in antitumor immunity. Nat Immunol. 2021;22:193-204.

131. DeVorkin L, Pavey N, Carleton G, Comber A, Ho C, Lim J, et al. Autophagy regulation of metabolism is required for $\mathrm{CD} 8(+) \mathrm{T}$ cell anti-tumor immunity. Cell Rep. 2019;27:502-13.

132. Hoglinger GU, Carrard G, Michel PP, Medja F, Lombes A, Ruberg M, et al. Dysfunction of mitochondrial complex $I$ and the proteasome: interactions between two biochemical deficits in a cellular model of Parkinson's disease. J Neurochem. 2003;86:1297-307.

\section{ACKNOWLEDGEMENTS}

The authors thank Linda V. Sinclair for critical reading and insightful feedback on the manuscript. We also thank members of the Cantrell group for valuable discussions on the topics covered. DAC is supported by a Wellcome Trust Principal Research Fellowship (205023/Z/16/Z), and JMM is supported by an Australian NHMRC CJ Martin Early Career Fellowship. Figures were created using BioRender.com. Figure 1a 
was adapted from the template "Protein Translation" by BioRender.com (2021) retrieved from https://app.biorender.com/biorender-templates.

\section{COMPETING INTERESTS}

The authors declare no competing interests.

\section{ADDITIONAL INFORMATION}

Correspondence and requests for materials should be addressed to Doreen $A$ Cantrell.

Reprints and permission information is available at http://www.nature.com/reprints
Open Access This article is licensed under a Creative Commons Attribution 4.0 International License, which permits use, sharing, adaptation, distribution and reproduction in any medium or format, as long as you give appropriate credit to the original author(s) and the source, provide a link to the Creative Commons license, and indicate if changes were made. The images or other third party material in this article are included in the article's Creative Commons license, unless indicated otherwise in a credit line to the material. If material is not included in the article's Creative Commons license and your intended use is not permitted by statutory regulation or exceeds the permitted use, you will need to obtain permission directly from the copyright holder. To view a copy of this license, visit http://creativecommons. org/licenses/by/4.0/.

(c) The Author(s) 2021 